If we dissolve a substance and allow it to crystallize, we get crystals of every shape, size, and description; and if we sil. verize a plate of copper, we shall find the forms of leaves, trees, and shrubs imprinted on the metal, which shows the tendency of mineral matter to run into vegetable matter, and this result is no doubt effected by the polarization I have spoken of. I believe that no representative of animal structure has been obtained in this manner, and for that reason among others I am inclined to say that animal life begins with vegetable life.

Shonld it be said that my theory ignores the act of God in the creation of the animal world, I answer in the negative. Polarization may be considered not only the origin of life, but the essential attribute of Deity; for all things - even rude matter itself-have come from God. But as 1 have entered very fully into this part of the subject in my work on the "Philosophy and History of Civilization," to which I must refer your readers, I will not enlarge upon it here.

If $\dot{I}$ am now asked why we do not see fishes, birds, animals, and men spontaneously produced at the present time as I bave supposed them to have been produced in the geological periods of bygone ages, I answer that the circumstances fitted to call forth these superior animals do not now exist, and have not existed perhaps for a hundred thousand years back.

Presuming that the last creations of superior animals and men took place in the period of the London Clay-which is more than probable, as shown by Sir Charles Lyell in his recent work on the "Antiquity of Man,"-let me ask, what was the state of nature then, compared with what it is now? In the London Clay period the climate was hot all over the globe; for we find the remains of elephants, apes, and other tropical ani. mals in Lapland and Siberia This great heat, in connexion with a thick atmosphere highly charged with oxygen and car bon, and tropical rains, untempered by cold winds or frost and snow, would produce an amount of vegetation which must ever be incomprehensible to us who have no experience of such a state of things in any part of the globe. This state of nature gave rise to creations of men and superior animals. which the present state of things is quite incapable of producing.

Although heat and moisture are the great agents for the production of life, they are nothing more than agents; for life itself comes, as I have said, from the polarization of nature.

Such is my theory of the origin of creation, and I shall be glad to hear the opinions of any of your numerous readers on the subject.

Sloane-street, March, 1863. Yours very respectfully,

A. Alisor.

\section{VALUE OF ALKALIES IN RHEUMATISM.} To the Editor of The LANCET.

Str,-I hope you will make room for a few explanatory observations, which are called forth by the letter of Dr. Fuller in your journal of the 21st ult. On the 7th of March I received a letter from an old professional friend, dated March 6th, in which he says :-

"I do not know whether you have seen some remarks by Dr. Fuller on the preventive power of alkalies in rhenmatic cardiac complications. Recollecting the trouble you took with respect to these subjects in former years, and seeing no allusion to your name, I wrote a letter to The LANCET, signed 'M.D. Retrospiciens.' Very possibly Dr. Fuller may not have read your observations on these subjects; but nevertheless I thought it but right to state your priority of claim. I trust this will not annoy you, as I thought it was but doing justice to you. "I am, Sir, your obedient servant,

" E. P. Houghton, M.D. "Formerly of Clay Cross, Derbyshire."

I had never seen Dr. Fuller's book and observations, of which, until Dr. Houghton wrote to me, I knew nothing. For many years before $1844 \mathrm{I}$ had been deeply and painfully im. pressed with the sufferings (chiefly of the poorer classes) from heart disease, caused by rheumatisu, and, reflecting on the de ficiency of alkalies in the body, rendered evident by the ap pearance of free acids in the secretions and excretions, and also on the normal alkalinity of the blcod, preventing an undue predominance and probable deposits of tibrin, I tried alkalies perseveringly, as likely to correct the ahnormal state. For years after this treatment $I$ had not-nor have I up to the pre sent time-met with one case of rheumatic fever in which disease of the heart occurred. I then published two articles in The LANCET, in 1844, and they attracted some attention. Dr. Wilson, of Sr. George's, wrote to object that I had not given analyses of rheumatic blood, which I assuredly should have done had I possessed sufficien 1. knowledge of practical chrmis. try; so I published the articles with a "valeat quantum," re. gretting my inability to analyze. Since then my views and opinions have been corroborated very strongly by Drs. Wright, Garrod, and others.

In 1845, Dr. Fuller says he first had recourse to full and repeated doses of alkalies and neutral salts, less than a year after my articles in THE LANCE'r. In 184', I published and ndvertised my book on "Diseases of the Heart, and the Use of Alkalies in Rheumatism as Preventives of Cardiac Mischief," wherein were "details of treatment," and something more than a mere "foreshadowing of the results of treatment" elaborated in Dr. Fuller's work on rheumatism, since my opinions and reasons were very distinctly, very fully, and de cidedly there laid down. Yet, notwithstanding these dates, it appears Dr. Fuller never rear my observations or book, and had (in not merely a "clinical lecture," but in a treatise on the subjects), published a munograph on them, without any allusion to my previous labours; and my friend thought I ought not to be so passed over.

These are the simple facts.

Let me, in conclusion, express the pleasure I feel on seeing the alkaline treatment of rheumatism now generally prevalent as a cardinal point of treatment, confident and hopeful as I am that much suffering and misery may be therehy prevented, and that the greater the number of medical practitioners who prescribe alkalies may be, the greater will be the accruing benefit. I am, Sir, your obedient, servant,

J. J. FurNivali, M.D.

Alexander-street, Westbourne-park, Bayswater, March, 1863.

\section{THE WAKLEY TESTIMONIAL.}

At a meeting held at the house of Mr. Hancock on the evening of the 20th current, the Hon. Secretary (Mr. D. O. Edwards) presented a report on the past proceedings. This report stated that some practitioners of the metropolis had thought it desirable that some testimonial should be presented to $\mathrm{Mr}$. Wakley, as an acknowle:lgment of his great public ser. vices. This proposition was widely accepted by the medical profession, and two hundred influential gentlemen formed them. selves into a general committee for the purpose of carrying it out. It was resolved that a suggestion should be made for the limitation of the subscription to two guineas individually, which had the effect of materially curtailiing the amount. A meeting was held, at which highly complimentary resolutions were passed and subscriptions were received.

The auditors' report was read, vouching the accounts.

The following resolutions were then passed:-

1. "That the report read be adopted, and that the funds collected be offered to the University of London, to be vested in trustees, and for the purpose of founding an annual Medal Prize, to be called the Wakley Medal, and to be given to the candidate for the M.B. degree of the University of London who shall show the greatest proficiency in Medical Jurispradence."

2. "That the Chairman, Treasurers, and Secretaries be requested to confer with the authorities of the University of London on the above subject."

3. "That the members of the General Committee and all others who have promised subscriptions be requested to forward the same, and that further subscriptions be received up to May 30 th, after which date the lists will be closed. Subscriptions may be paid to the above account at Messrs. Drummond and Co., Charing-cross, or to the Treasurers, Dr. Forbes Winslow, Cavendish-square, and Mr. Godrich, Thistlegrovehouse, West Brompton,"

4. "That the thanks of the meeting be giren to the Treasurers and Secretaries for their exertions in promoting the movement, and that those thituks are especially due to Mr. Godrich and Mr. D. O. Edwards, by whose exertions it has been chiefly advanced."

5. "That the thanks of the meeting are due, and are hereby tendered, to $\mathrm{Mr}$. Hancock, the Chairman of the present meeting, for his courteous and dignifer conduct in the chair."

UNIVERITY of ST. ANDREWS.-The examination for the degree of Doctor of Medicine will take place on Monday and Tuesday next, the 27 th and 28 th inst. 